\title{
Adrenal Carcinoma - A Case Report
}

\author{
MAHBUB MUTANABBI ${ }^{1}$, MD. ATIAR RAHMAN ${ }^{1}$, SM BAQUI BILLAH ${ }^{2}$, MD. AL HELAL ${ }^{3}$, MD. HAFIZ AL \\ MAMUN $^{3}$, KHANDAKER EHSANULAREFIN $^{4}$
}

\section{Introduction:}

Adrenal cortical cancer arises from the cortex of the adrenal gland. This tumour can occur in children and in adults. Adrenocortical tumours are common tumours with a prevalence of at least $3 \%$ in a population over the age of $50 \mathrm{yr}^{1}$. In contrast, adrenocortical carcinoma (ACC) is a rare malignancy (incidence 1-2 per 1 million population) with a heterogeneous presentation and a variable but generally poor prognosis ${ }^{2}$. However, data on incidence are mainly based on the National Cancer Institute survey from the early 1970 s and probably underestimate the true incidence. An exceptionally high annual incidence of ACC has been reported for children in Southern Brazil (3.4-4.2 per 1 million children vs. an estimated worldwide incidence of 0.3 per 1 million children younger than $15 \mathrm{yrs}$ of age) and is related to a TP53 tumour suppressor gene mutation $^{3}$. Women are more often affected than men (ratio 1.5) $)^{4,5,6}$. The age distribution is reported as bimodal with a first peak in childhood and a second higher peak in the fourth and fifth decade ${ }^{2,6}$

\section{Case Report:}

A $3 \frac{1}{2}$ years old girl of nonconsanguineous parents, was admitted in Bangabandhu Sheikh Mujib Medical University with the complaints of appearance of pubic hair and gradual enlargement of clitoris for 8 months and gradual deepening of voice for 3 months(Fig-1). The voice of the baby gradually deepened and changed to male pattern. She also had itching in and around the vulva. She had no history of menstrual bleeding or breast enlargement, no history of headache, vomiting, convulsion or ingestion of any offending drug. On examination-she had a male type of figure with wide chest and widely spaced nipples and muscular body build (Fig-2). Her abdomen was protuberant. BCG mark

1. Assistant Professor of Paediatrics, Bangabandhu Sheikh Mujib Medical University, Shahbag, Dhaka.

2. Senior Consultant of Paediatrics, Bangabandhu Sheikh Mujib Medical University, Shahbag, Dhaka.

3. Consultant of Paediatrics, Bangabandhu Sheikh Mujib Medical University, Shahbag, Dhaka.

4. Medical Officer of Paediatrics, Bangabandhu Sheikh Mujib Medical University, Shahbag, Dhaka.

Correspondence: Dr. Mahbub Mutanabbi

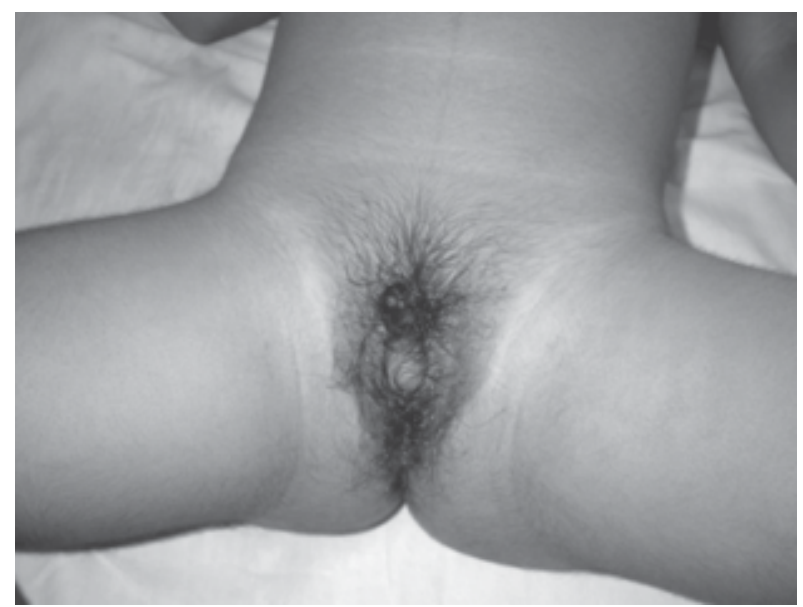

Fig. 1: Male type of genitalia with early appearance of secondary sexual characteristics

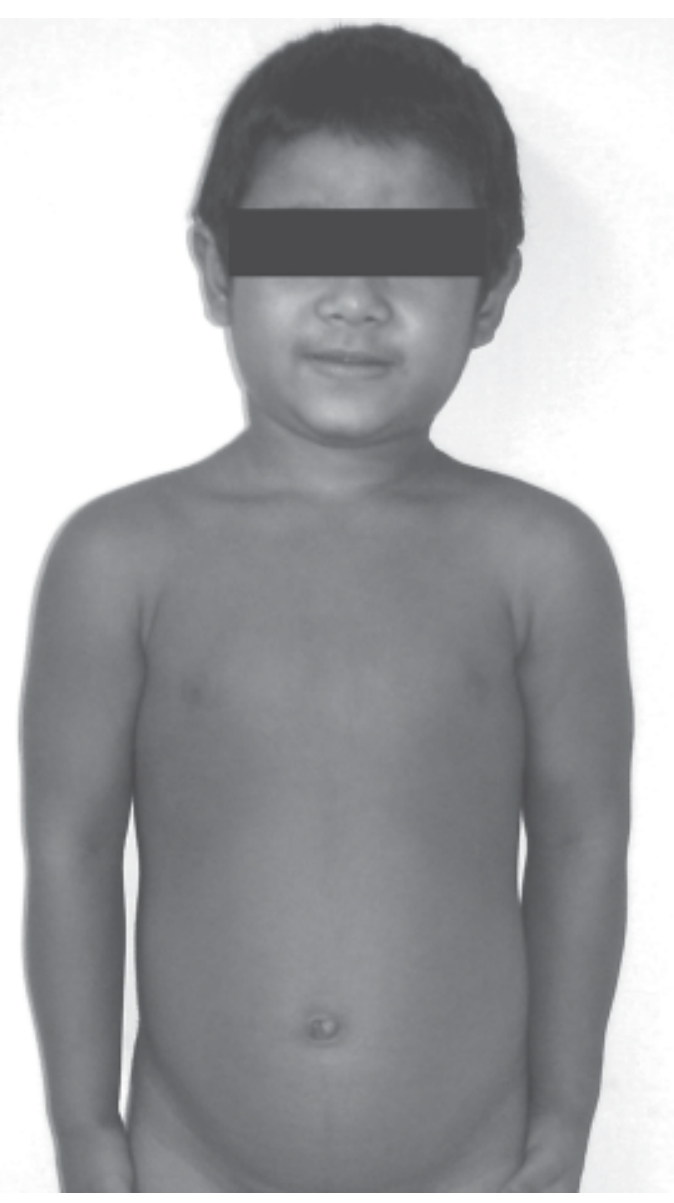

Fig. 2: Masculin features of the patient 


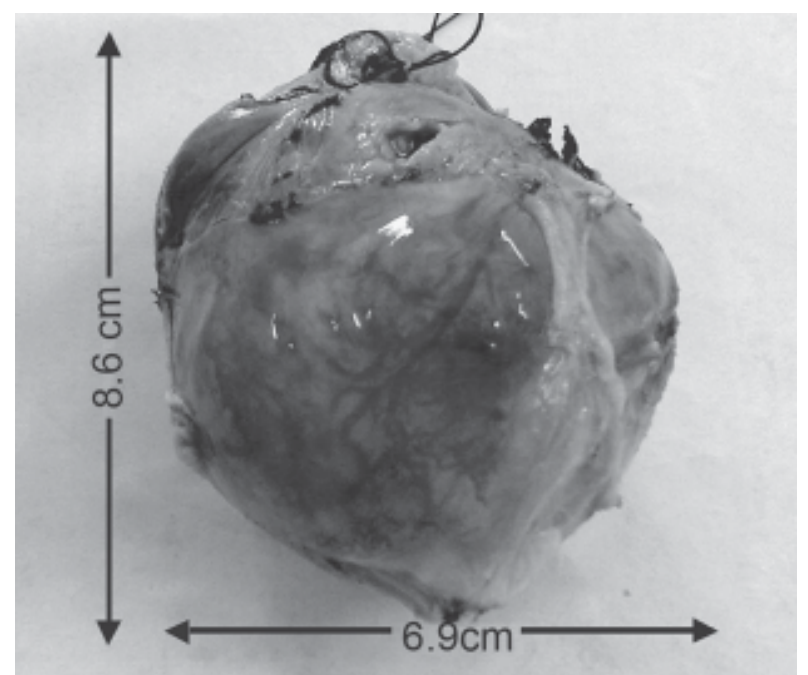

Fig. 3: Adrenal mass after excision

was present, increased body hair, axillary hair began to appear and pubic hair distribution was adult male pattern. Pulse was 100 beats/min, Blood pressure was-100/60 mm of $\mathrm{Hg}$. Her weight was $20 \mathrm{~kg}$, height was $104 \mathrm{~cm}$. Weight for age Z-score (WAZ) was +3.7, Weight for height $Z$-score was $(\mathrm{WHZ})=+1.58$, Height for age $Z$-score (HAZ) was +2 . On systemic examination- Clitoris was enlarged resembling penis which was about $3.5 \mathrm{~cm}$ in length, pubic hair coarse, curly, vaginal orifice intact and urethral orifice normal in position. There was no breast bud, SMR was B1A2-P3. Examinations of other systems revealed nothing abnormal.

The baby was investigated for complete blood count. Hemoglobin ( $\mathrm{Hb}$ ) was $13 \mathrm{gm} / \mathrm{dl}$, ESR was $10 \mathrm{~mm}$ in the first hour. Total count of WBC was $10000 / \mathrm{cmm}$ with differential count Neutrophil -42\%, lymphocyte $52 \%$, monocyte-03\%, eosiphil-03\%. Platelet count was 250000/cmm, peripheral blood film (PBF) showed non specific morphology.In Urine R/E Pus cell was found 2-3/HPF, Epithelial cell was 1-2/ HPF, The report of serum electrolytes was $\mathrm{Na}^{+} 139 \mathrm{mmo} / \mathrm{l}, \mathrm{K}^{+}-4.8 \mathrm{mmo} /$ I, $\mathrm{Cl}^{-} 100 \mathrm{mmo} / \mathrm{l}$, Serum total $\mathrm{CO}_{2}-22 \mathrm{mmol} / \mathrm{L}$. Random blood sugar was $4.6 \mathrm{mmol} / \mathrm{L}$. S. bilirubin was 12umol/L. serum ALT -32U/L. Chest X-ray p/A view was normal. X-ray wrist joint showed appearance of 8 carpal bones which corresponds to 9 years of age. Dehydroepialdosterone (DHEA) level was raised (13.5 $\mathrm{ng} / \mathrm{dl}$ ). USG of whole abdomen showed a solid echogenic mass measuring about $8.6 \times 6.9 \mathrm{~cm}$ in the right hypochondriac region in the upper pole of right kidney. It occupied the right adrenal area and lateral aspect of right lobe of liver. For resection of the tumour and getting specimen for histopathology the patient was referred to paediatric surgery unit.

After operation a mass of $8.6 \times 6.9 \mathrm{~cm}$ was removed (Fig-3). It seemed to arise from right adrenal gland extending up to nearby structures. It was categorized as stage III. Dehydroepiandrosterone (DHEA) measured after operation was within normal limit (1.05ng/dl). Histopathology (of adrenal mass): on gross examination- showed an irregular gray white piece of tissue (part of a mass) measuring $2.5 \times 2 \times 1.2$ $\mathrm{cm}$ partly encapsulated, weight $10 \mathrm{gm}$, surface was brownish and glandular. Microscopic examination showed a malignant tumour composed of adrenocortical cells. The tumour cells were arranged in nets and trabecular pattern. Many bizzare monstrous giant cells were seen. Areas of necrosis were also seen. These findings were consistent with adrenocortical carcinoma. After confirming the diagnosis the patient was discharged and advised to get admission in Paediatric Haemato-oncology department of Bangabandhu Sheikh Mujib Medical University for chemotherapy and further management.

\section{Discussion:}

Adrenal carcinoma usually presents with evidence of adrenal steroid hormone excess in approximately $60 \%$ of cases. Rapidly progressing Cushing's syndrome with or without virilization is the most frequent presentation. In patients from the German adrenocortical carcinoma (ACC) registry, autonomous cortisol secretion, either alone or in combination with other steroids, was detectable in $60 \%$ of the cases in which hormonal analysis had been performed prior to surgery ${ }^{6}$. However, not in all of these cases autonomous cortisol secretion was clinically suspected. Androgen secreting adrenocortical carcinomas (ACCs) in women induce hirsutism and virilization with deepening of the voice, male pattern baldness and oligoamenorrhea. Our patient presented with appearance of pubic hair, gradual enlargement of clitoris and gradual deepening of voice.

Estrogen-secreting adrenal tumours in males lead to gynecomastia and testicular atrophy and are almost invariably malignant ${ }^{7}$. High concentration of dehydroepiandrosterone sulfate (DHEA-S) is another clue suggesting adrenocortical carcinoma (ACC), whereas decreased serum DHEA-S concentrations are suggestive of a benign adenoma ${ }^{7}$ Aldosteroneproducing adrenocortical carcinomas present with hypertension and pronounced hypokalemia (mean 
serum potassium $2.3 \pm 0.08 \mathrm{mmol} /$ liter $)^{8}$ However, severe hypokalemia is more likely to be caused by grossly elevated cortisol secretion, leading to insufficient renal cortisol inactivation by $11 \hat{a}-$ hydroxysteroid dehydrogenase type 2 with consecutive activation of the mineralocorticoid receptor. In many patients with a seemingly hormonally inactive adrenocortical carcinoma (ACC), high concentrations of steroid precursors like androstenedione or 17áhydroxyprogesterone can often be demonstrated, thereby establishing the adrenocortical origin of the tumour. Hormonally inactive adrenocortical carcinomas (ACCs) usually present with abdominal discomfort (nausea, vomiting, abdominal fullness) or back pain caused by a mass effect of the large tumour. But our patient did not present with these complaints. So it appeared that the patient did not have a hormonally inactive tumour. In the Italian survey on adrenal incidentaloma, the occurrence of pain was significantly associated with adrenocortical carcinoma (ACC) and was not fully explained by large tumour size per $\mathrm{se}^{9}$ However, an increasing percentage of adrenocortical carcinomas (ACCs) is discovered as incidentaloma during abdominal imaging ${ }^{9}$. Only occasionally patients present with fever, weight loss, and anorexia, and it is a remarkable feature of noncortisol-producing adrenocortical carcinoma (ACC) that well-being is often little affected by even a large tumour burden.

The molecular pathogenesis of adrenocortical carcinoma (ACC) has been the topic of recent reviews ${ }^{10}$ but is still poorly understood. It is unclear whether adrenocortical carcinomas (ACCs) evolve from adrenal adenomas after a second hit paradigm. Although such a sequence has been observed in occasional cases ${ }^{11}$, long term follow-up data of incidentally discovered adrenal neoplasms suggest otherwise ${ }^{12}$ Inactivating mutations at the $17 \mathrm{p} 13$ locus including the TP53 tumour suppressor gene and alterations of the 11p15 locus leading to IGF-II over expression are frequently observed. In vitro experiments suggest that overexpressed IGF-II acting via the IGF-I receptor is relevant for adrenal cancer cell proliferation ${ }^{13}$. Thus, the IGF-II IGF-I receptor pathway is a promising target for future therapies in adrenocortical carcinoma (ACC) $)^{14}$.

Until 2004, no official tumour nodes and metastasis (TNM) classification was available for adrenocortical carcinoma (ACC), and different staging systems were used $^{15,16}$, most often the Sullivan modification of the Macfarlane system. Accordingly, the new Union International Centre Cancer (UICC) staging system published by the World Health Organization (WHO) in 2004 is based on this classification ${ }^{17}$. Stages I and II describe localized tumours $5 \mathrm{~cm}$ or smaller and larger more than $5 \mathrm{~cm}$, respectively. Locally invasive tumours or tumours with regional lymph node metastases are classified as stage III, whereas stage IV consists of tumors invading adjacent organs or presenting with distant metastases. However, the prognostic value of the different staging systems has never been compared directly in a large series of patients. Because one of the major objectives of staging classifications is to facilitate the exchange of information between treatment centers, we currently recommend the use of the new WHO system until evidence that a modification is needed becomes available. Whereas in older series ${ }^{4,15}$ most patients were diagnosed with advanced disease (stage IV), recent studies have reported the highest percentage of patients in stage $\|^{5,18}$, most likely reflecting improved and more widely available imaging technology.

Treatment of adrenocortical carcinoma begins with surgical care. Surgery is the mainstay of treatment and currently appears to be the major hope for cure. Every reasonable attempt should be made to render the patient disease-free at the primary sites of local invasion and at sites of metastatic disease. When metastatic disease cannot be removed or when biochemical evidence of tumours secretion persists after surgical removal, chemotherapy is often considered. Our patient presented with those problem which corresponded with other reports. According to the clinical presentation and laboratory findings this patient can be categorized as stage-lll. After confirming diagnosis, total resection of adrenal mass was done. On follow up her condition was stable along with disappearance of secondary male characteristics.

\section{References}

1. National Institutes of Health, NIH state-of-thescience statement on management of the clinically inapparent adrenal mass ("incidentaloma"). NIH Consens State Sci Statements 2002; 19: 1-25.

2. Wajchenberg $B$, Albergaria PM, Medonca B, Latronico A, Campos CP, Ferreira AV, et al. Adrenocortical carcinoma: clinical and laboratory observations. Cancer 2000; 88:71 1-736. 
3. Ribeiro RC, Sandrini F, Figueiredo B, Zambetti GP, Michalkiewicz E, Lafferty AR, et al. An inherited p53 mutation that contributes in a tissue-specific manner to pediatric adrenal cortical carcinoma. Proc Natl Acad Sci USA 2001; 98: 9330-9335.

4. Wooten MD, King DK, Adrenal cortical carcinoma. Epidemiology and treatment with mitotane and a review of the literature. Cancer 1993; 72:3145-3155.

5. Icard P, Goudet P, Charpenay C, Andreassian $B$, Carnaille B, Chapuis Y, et al. Adrenocortical carcinomas: surgical trends and results of a 253 patient series from the French Association of Endocrine Surgeons Study Group. World J Surg 2001; 25:891-897.

6. Koschker AK, Fassnacht M, Hahner S, Weismann D, Allolio B. Adrenocortical carcinoma improving patient care by establishing new structures. Exp Clin Endocrinol Diabetes,2006; 144: 45-51.

7. Fassnacht M, Kenn W, Allolio B. Adrenal tumors: how to establish malignancy? Endocrinol Invest 2004; 27: 387-399.

8. Seccia TM, Fassina A, Nussdorfer GG, Pessina AC, Rossi GP. Aldosterone-producing adrenocortical carcinoma: an unusual cause of Conn's syndrome with an ominous clinical course. Endocr Relat Cancer 2005; 12: 149-159.

9. Mantero F, Terzolo M, Arnaldi G, Osella G, Masini AM, Ali A, et al. A survey on adrenal incidentaloma in Italy. Study Group on Adrenal Tumors of the Italian Society of Endocrinology. J Clin Endocrinol Metab 2000; 85:637-644.

10. Koch CA, Pacak K, Chrousos GP. The molecular pathogenesis of hereditary and sporadic adrenocortical and adrenomedullary tumors. J Clin Endocrinol Metab 2002; 87:5367-5384.
11. Bernard MH, Sidhu S, Berger N, Peix JL, Marsh DJ, Robinson BG, et al. A case report in favor of a multistep adrenocortical tumorigenesis. J Clin Endocrinol Metab 2003; 88: 998-1001.

12. Barzon L, Scaroni C, Sonino N, Fallo F, Paoletta A, Boscaro M. Risk factors and long-term followup of adrenal incidentalomas. J Clin Endocrinol Metab 1999; 84: 520-526.

13. Logie A, Boulle N, Gaston V, Perin L, Boudou P, Le Bouc $Y$ et al. Autocrine role of IGF-II in proliferation of human adrenocortical carcinoma $\mathrm{NCl} \mathrm{H295R} \mathrm{cell} \mathrm{line.} \mathrm{J} \mathrm{Mol} \mathrm{Endocrinol} \mathrm{1999;} \mathrm{23:}$ 23-32.

14. Kirschner LS. Emerging treatment strategies for adrenocortical carcinoma: a new hope. J Clin Endocrinol Metab 2005; 91: 14-21.

15. Macfarlane DA. Cancer of the adrenal cortex: the natural history, prognosis and treatment in a study of fifty-five cases. Ann R C Surg Engl 1958; 23:155-186.

16. Icard P, Chapuis Y, Andreassian B, Bernard A, Proye $\mathrm{C}$. Adrenocortical carcinoma in surgically treated patients: a retrospective study on 156 cases by the French Association of Endocrine Surgery. Surgery 1992; 112: 972-979.

17. DeLellis RA, Lloyd RV, Heitz PU, Eng C. World Health Organization classification of tumours. Pathology and genetics of tumours of endocrine organs. Lyon, France; IARC Press 2004.

18. Bellantone $\mathrm{R}$, Ferrante A, Boscherini $\mathrm{M}$, Lombardi CP, Crucitti P, Crucitti F, et al. Role of reoperation in recurrence of adrenal cortical carcinoma: results from 188 cases collected in the Italian National Registry for Adrenal Cortical Carcinoma. Surgery 1997; 122: 1212-1218.

19. Luton J, Cerdas S, Billaud L. Clinical features of adrenocortical carcinoma, prognostic factors, and the effect of mitotane therapy. N Engl J Med 1990; 322: 1195-1201. 